\title{
On the presuppositional behavior of coherence-driven pragmatic enrichments
}

\author{
Andrew Kehler \\ Jonathan Cohen \\ University of California, San Diego University of California, San Diego
}

\begin{abstract}
When interpreting a sentence such as Every time the company fires an employee who comes in late, a union complaint is lodged, an addressee is likely to infer that the union will only complain when an employee is fired because he came in late. One is thus led to ask why a purely pragmatic enrichment of this sort - one drawn despite no risk of interpretative failure nor other linguistic mandate - would intrude upon truth conditions. We argue that this effect results from the interaction among three pragmatic phenomena: presupposition, the associative mechanisms that underlie the establishment of coherence in discourse, and the calculation of domain restriction for quantificational operators. Because the analysis does not consider the operative enrichments to be species of implicature, we claim that such cases do not represent an intrusion of implicature into truth-conditional content. Instead, they merely involve the context-dependent determination of quantificational domains.
\end{abstract}

Keywords: pragmatic enrichment, presupposition, domain restriction, discourse coherence

\section{The puzzle}

Consider (1) and (2):

(1) Every time the company fires an employee who comes in late, a union complaint is lodged.

(2) If the company fires an employee who comes in late, a union complaint will be lodged.

After taking a moment to ruminate on what these sentences mean, consider Snodgrass's Situation. The company Snodgrass worked for discovered that he was embezzling money, and decided they needed to fire him when he next came to work. And sure enough, when he did come in - 15 minutes late, as it so happens - he was promptly dismissed. Snodgrass's union of course caught wind of this, but after considering the details of the situation and the evidence against their member, opted to do nothing. 
Could (1) and (2) still be judged true on this scenario? One might well think not. After all, Snodgrass was an employee who came in late and got fired, hence satisfying the domain restriction and antecedent of (1) and (2) respectively, yet the union failed to act in the manner specified. Our intuitions nonetheless tell us that they can in fact still be judged true: whereas Snodgrass was fired and he came in late, he was not fired because he came in late. As such, there is a pragmatic enrichment at play; one that leads us to judge that the situation sits outside of the domain restriction of (1) and the antecedent of the conditional in (2). The enrichment has no linguistic mandate - it results from drawing an association between the meanings of two constituents for which there is no direct relationship in the syntax, specifically a matrix verb and a relative clause that modifies the object noun phrase. So why does this enrichment intrude upon the truth conditions of (1) and (2)?

According to the analysis that follows, this effect results from the interaction among pragmatic presupposition, the associative mechanisms that underlie the establishment of coherence in discourse, and the calculation of domain restriction. In particular, in producing examples (1) and (2) with the intention to convey the enrichment, a speaker pragmatically presupposes that a defeasible causal relation necessary for the hearer to make the inference is part of the common ground, and further intends it to restrict the set of situations over which the quantifier in (1) and the antecedent of (2) are evaluated. The analysis connects the associative inferences that underlie the establishment of coherence relations between sentences in a discourse, a class of intrasentential enrichments that result from the same principles, and the manner in which pragmatic inferences that originate from presuppositions restrict the domains of conditionals and quantified expressions. We consider these topics in turn.

\section{Coherence establishment}

According to Stalnaker (1979), the assertion of natural language utterances provides a way for a speaker to constrain the set of possible worlds that her hearer will entertain as being the actual one. However, it has long been noted (Hobbs 1990; Kehler 2002; Asher \& Lascarides 2003; inter alia) that, when presented with co-occurring utterances in a discourse, comprehenders are not content to merely update their world models with the meanings of each utterance. Instead, they seek to establish some sort of semantic relationship - a COHERENCE RELATION — between them. Consider (3a), for example.

(3) a. The company fired the employee. He came in late.

b. ? The company fired the employee. He has red hair.

Addressees will typically infer an EXPLANATION coherence relation for (3a), 
whereby the second sentence expresses the cause or reason for the event described in the first.

EXPLANATION: For eventualities $e_{1}$ and $e_{2}$ described by utterances $S_{1}$ and $S_{2}$ respectively, infer that cause $\left(e_{2}\right)\left(e_{1}\right)$.

Crucially, the ability to infer a causal relationship is not unconstrained: it relies on certain beliefs being in the common ground, in this case, that being late to work could cause one to be fired. This is what goes wrong for (3b), as world knowledge typically does not similarly associate having red hair and getting fired. This fact is likewise contingent on the beliefs of the interlocutors, however: If it is in the common ground that the CEO despises redheads (after all, her former husband ran off with one), the passage may well be coherent after all.

Axiom (4) represents a possible encoding of an associative rule that captures the relationship between being late to work and getting fired.

$$
\begin{aligned}
\lambda s . \forall s^{\prime}\left[\operatorname{Acc}_{\mathrm{C}}(s)\left(s^{\prime}\right) \&\right. & \\
\forall x, e_{1}, e_{2} \leq_{p} s^{\prime} & {\left[\text { employee }(x) \text { \& come_in_late }\left(e_{1}\right)(x) \&\right.} \\
& \quad \text { fire }\left(e_{2}\right)(\text { employer }(x))(x) \& t_{e_{1}}<t_{e_{2}} \\
& \left.\left.\Rightarrow \text { cause }\left(e_{1}\right)\left(e_{2}\right) \leq_{p} s^{\prime}\right]\right]
\end{aligned}
$$

Axiom (4) is articulated in terms of a situation semantics, although nothing we say below hangs on this implementational choice. Let us take a moment to unpack the rule. Suppose that we have an agent who is working at a company and sees an employee come in late, and soon thereafter, get fired. Rule (4) captures the default inference that the agent is likely to make, i.e., that the coming in late caused the firing. Specifically, it says is that in any situation (subject to the accessibility condition Acc; more on this below) in which an employee comes in late and subsequently ${ }^{1}$ gets fired, one can conclude that the two events are causally related. On the other hand, as mentioned above, our agent's knowlege store will typically not contain a similar rule that causally relates having red hair and getting fired. Hence, under normal circumstances, when one witnesses someone get fired who happens to have red hair, no causal inference is drawn.

Of course, such rules are defeasible - it is certainly not true in all situations (Snodgrass's, for example) in which the events of being late and getting fired occur that the two are causally related. We capture this property by borrowing tools from the Kratzerian theory of modals (Kratzer 1981). Consider the situation in which our agent, having witnessed the sequence of events just described, utters (5).

1 The ordering restriction on event times in (4), while satisfiable in our non-linguistic scenario, may not always be entailed by the denotation of a linguistic description of the scenario. In such cases, the ordering will have to be accommodated by the hearer, outside of information to the contrary. 
(5) Snodgrass must have gotten fired because he came in late.

Surely our agent is not using must to mean that it is impossible that Snodgrass got fired for some other reason. Instead she is saying that it must be the case as long as one makes certain assumptions about the situation, e.g., that events bear stereotypical associations with one another. Kratzer's theory captures this effect by interpreting sentences like (5) against two sets of propositions (termed CONVERSATIONAL BACKGROUNDS). The first background constitutes the modal base, which here we take to be epistemic - the set of facts known to the interlocutors about the situation they are in. The second background constitutes the ordering source, which we take to be stereotypical - those situations that correspond to the normal course of events. Interpreted against these backgrounds, (5) therefore says that in all of the situations consistent with what we know and that are closest to the ideal - which, following Portner (2009), we refer to as the BEST situations - Snodgrass was fired because he came in late. For simplicity, we capture the joint effects of these backgrounds in terms an accessibility relation (Acc) on situations (see also Toosarvandani (2014), who represents causal laws in a similar manner). Note that if it were to subsequently come to be known to the discourse participants that Snodgrass was fired because he was embezzling money, sentence (5) could no longer be considered to be true. Here, the occurrence of the embezzling and the causal relationship between the embezzling and the firing would become part of what is known, and hence added to the modal base. Per what is stereotypical about such situations, the proposition that the lateness caused the firing would no longer be contained in the best situations per the ordering source.

Axiom (4) comes into play during the interpretation of our examples in a similar manner. Specifically, we argue that a speaker who utters (3a), and does so with the intention that the appropriate coherence relation be established by the addressee, pragmatically presupposes (Stalnaker 1974, 1998) that the knowledge captured by (4) is in the common ground. The addressee, who is trying to understand the situation being described, recognizes that (4) provides the basis for inferring that the situation includes a causal relation between the events, in the absence of information to the contrary. Assuming further that it was the speaker's intention to convey that relation, the hearer thus draws the causal inference. The inference of causality in turn satisfies the constraints associated with the Explanation relation, allowing for the coherence of the passage to be established.

The idea that presupposition is at play in examples like (3a) receives partial (if not conclusive) support from application of the "Wait a minute" test (Shanon 1976; von Fintel 2004). ${ }^{2}$ To see how the test works, consider (6a) which, per a

2 Another standard diagnostic for presuppositional status - the so-called family-of-sentences test relies on projection behavior in a range of embedding environments (see Chierchia \& McConnell- 
common analysis of the verb stop, not only asserts that Snodgrass does not smoke, but presupposes that he used to. Despite the fact that the denial in (6b) fails to contradict the assertion of (6a), it is perfectly felicitous. Its felicity results from the fact that it denies what is presupposed by the utterance of (6a).

a. A: Snodgrass stopped smoking.

b. B: Hey, wait a minute. Snodgrass never smoked to begin with!

Analogously, (7) provides a felicitous a response to (3a) despite failing to contradict either of its assertions.

(7) Hey, wait a minute. Union rules don't allow someone to be fired for coming in late!

Instead, it targets the stereotypical connection between lateness and firing that our speaker presupposes when uttering (3a) - i.e., that (4) is mutually believed and applicable to the situation. Importantly, what is presupposed here is only the defeasible causal law. The fact that it applies to the employee mentioned in (3a) is a pragmatic enrichment that is made in light of this law, i.e., it is not itself presupposed.

Our claim that the constraints associated with coherence relations are presuppositional is supported by the behavior of other, non-causal relations. Consider (8a):

(8) a. Country singers sometimes sell more albums than your typical pop star. Taylor Swift's latest album sold 9 million copies.

b. Hey, wait a minute. I thought Swift was a gospel singer!

On its most natural interpretation, example (8a) is understood as instantiating an EXEMPLIFICATION relation:

EXEMPLIFICATION: Infer $p\left(a_{1}, a_{2}, \ldots\right)$ from the assertion of $S_{1}$ and $p\left(b_{1}, b_{2}, \ldots\right)$ from the assertion of $S_{2}$, where $b_{i}$ is a member or subset of $a_{i}$ for some $i$.

That is, Exemplifications are characterized by a general statement followed by a more specific instantiation of it. When a speaker utters (8a), she is presupposing the information necessary to satisfy the constraints associated with the relation in this case, that Taylor Swift is an example of a country singer, and that 9 million copies is an example of more albums than a typical pop star sells. Importantly,

Ginet (2000) for discussion). Unfortunately this test appears to be inapplicable to the intersentential cases under discussion here (e.g., (3a)), since there's no way to wrap the relevant linguistic environments (negation/question/negative quantifier/etc.) around two sentences at once. We make use of the family-of-sentences test in discussing the intrasentential examples in $\S 3$. 
neither of these relationships are entailed by the passage. And in the case that the addressee was unaware of either of these facts, he will presumably accommodate them fairly effortlessly without evidence to the contrary. The situation is entirely parallel to more familiar cases of presupposition accommodation, such as when a hearer accommodates that the speaker has a brother in reaction to her uttering $M y$ brother is coming to visit. Moreover, as before, a (here, confused) addressee could likewise respond to (8a) with the objection in (8b). Again, (8a) asserts nothing to the contrary; here the addressee's response targets the presupposition that Swift is a country singer.

Evidence that the presuppositions at play in these examples are pragmatic rather than semantic is provided by the fact that they satisfy various diagnostics indicative of pragmatic presupposition (Potts 2015). First, the ability to assign a truth value is not at stake as with semantic presuppositions; the source of the possible incoherence of ( $3 b$ ), for instance, does not arise from any inability to evaluate the truth of either of its clauses. Second, the presupposed content represents background beliefs of the speaker whose truths she takes for granted. Third, the status of particular examples can change across contexts without having to stipulate a semantic ambiguity; recall that the coherence of ( $3 b$ ) hinges on whether the context provides a basis for establishing a causal relationship between having red hair and being fired. Finally, the presuppositions are non-conventional, that is, they do not arise from the presence of any particular constituent.

\section{Conversational eliciture}

Thus far we have argued that coherence establishment involves a speaker's pragmatic presupposition of information that is necessary to establish the constraints associated with the coherence relation that the hearer is intended to recognize. A notable property of this process is that of being failure-driven: hearers must draw some type of coherence relation between adjacent sentences within a discourse segment in order to establish their coherence, lest they be left satisfied with discourses like (3b). A factor that no doubt aids in the inference to a cause in (3a) is the fact that the establishment of a coherence relation, in this case Explanation, comes for free, thereby rescuing the discourse from failure.

Perhaps surprisingly, we see the same types of inferences drawn between the meanings of constituents related intrasententially, in situations in which there is no risk of failure nor other linguistic mandate to trigger inferential machinery. For instance, an interpreter who hears sentence (9) is likely to enrich their interpretation of the situation being described to include a causal relationship between the lateness and firing by the same reasoning process that we characterized for (3a).

(9) The company fired the employee who came in late. 
This inference is defeasible: the sentence could be felicitously followed with the sentence The reason the employee was fired is that he had been embezzling money. This defeasibility is a direct result of the fact that, unlike the intersentential cases in (3a-b), the inference drawn was not in service of satisfying a felicity requirement.

As such, intrasentential examples that do not elicit analogous enrichments are nonetheless perfectly felicitous:

(10) The company fired the employee who has red hair.

As with (3b), the unavailability of a causal inference between having red hair and being fired is a result of the lack of the type of causal knowledge that we captured in (4). Unlike (3b), however, (10) is perfectly acceptable; here the relative clause is merely understood to be identificational. In other work we have branded the phenomenon that gives rise to such intrasentential, coherence-driven inferences with the label Conversational Eliciture (Cohen \& Kehler 2016), a term intended to capture the fact that, by choosing a particular form of reference, a speaker elicits inferences on the part of the hearer that would not otherwise be drawn.

The fact that (9) gives rise to the same inference as the intersentential case (3a) suggests that it relies on the same presupposed information. And as expected, we see that tests for presupposition are satisfied in the same way. For instance, (7), repeated below as (11), targets the presupposition associated with (9) in the same way that it does for (3a).

(11) Hey, wait a minute. Union rules don't allow someone to be fired for coming in late!

Again, (11) is felicitous despite its failure to contradict anything that (9) asserts.

As pointed out by Potts (2015), the "Wait a minute" test does not cleanly distinguish presuppositions from other information conveyed by utterances. Another canonical test is provided by the so-called "family of sentences": a collection of constructions from which presuppositions are known to project. Among these constructions are no-NP environments, never environments, questions, modals, and negation; these are employed in (12a-e) respectively.

(12) a. The company fired no employee who came in late.

b. The company never fires employees who come in late.

c. Did the company fire the employee who came in late?

d. The company might fire the employee who came in late.

e. The company didn't fire the employee who came in late.

We find that all of these give rise to the enrichment in question. This is particularly true for (12a-b) which, like (1-2), involve quantification, and hence according to our 
proposal can be understood to affect truth conditions (see §6). Specifically, it seems to us that these sentences could be judged true even in light of Snodgrass's Situation. The effect is predictably less strong in (12c-e) since the inferences in question are merely pragmatic enrichments, yet we find them to be there. For instance, when considering Snodgrass's Situation, question (12c) is unlikely to get a straight yes answer; it seems more likely that the answerer would want to cancel the eliciture: yes, but they fired him for embezzling.

In summary, we have argued that the same inference processes that underlie the establishment of coherence relations in intersentential cases like (3a) are those responsible for intrasentential cases of eliciture in cases like (9). Despite the lack of linguistic mandate in the case of eliciture, both phenomena involve a speaker's presupposition that certain types of world knowledge are in the common ground.

\section{Eliciture compared to other types of expansion}

A natural reaction to the types of inferences we have discussed is that they are the result of procedures that have been argued to underlie other sorts of pragmatic enrichment, such as from a violation of communicative norms based on principles of rationality/cooperativity (i.e., IMPLICATURE, Grice 1975), or the need to fill in a value for an otherwise unsaturated grammatical or semantic parameter (as in Bach's (1994) IMPLICITURE). Here we take a moment to argue that this line of thought does not go through, and hence defend our coinage of a new term to describe the process by which such inferences come about. The distinction between eliciture and these other types of enrichment is important to pin down when considering the issue of pragmatic intrusion into semantics (see $\S 7$ ). ${ }^{3}$

We first consider implicature. The central issue we see for an implicature analysis is that, according to Grice, the inference to extrasemantic content is the result of a rescue operation, triggered by the potential of norm violation. That is, as we understand it, the Gricean account of a hearer's inferential recovery of the content that a speaker intends to convey extrasemantically involves roughly the following four steps. First, the listener recovers the literal semantic content $p$ for the speaker's utterance, fixing reference and resolving ambiguity as necessary. Second, he notices that the content $p$, as expressed by the speaker in the operative circumstances, would violate one or more Gricean maxims. Third, since he takes it that speakers, given a presumption of cooperativity, ordinarily abide by these maxims, he infers that the speaker must also intend to convey some additional content $q$ whose expression in the circumstances would make the utterance consistent with the maxims. Finally, he therefore treats the utterance as conveying the maxim-compliant $q$ (perhaps in

3 These arguments are taken from, and elaborated upon in, Cohen \& Kehler 2016. 
combination with $p$ ).

The problem with construing eliciture in terms of implicature (so understood) is that it is hard to see what Gricean norm could trigger the inferences at play in examples like (9). Perhaps the first norm that emerges as a candidate is the Maxim of Relation, which implores the speaker to 'be relevant'. That is, one might react to (9) with the thought that, by virtue of selecting a particular relative clause to modify the object noun phrase over others that might have been possible, the choice of relative clause has to be explained by way of establishing its relevance to some other aspect of the sentence or discourse context. This story runs into an immediate problem, however, in that pedestrian examples such as (10) demonstrate that the function of allowing the addressee to identify the correct referent of the host noun phrase is sufficient to establish the relevance of a relative clause; no additional inference is necessary. But since the relative clause in example (9) serves this identificational role as well - from a set of employees, it will pick out the one who came in late we are left without an explanation for why additional inferences of the sort drawn for (9) would be necessary to satisfy the Relation/relevance maxim.

A second, and more general, problem is that it is unclear that there could be any antecedent trigger for the search for relevance other than the recognition of relevance itself. To see what we mean, consider sentences (13a-c).

a. The apprentice scheduled a meeting with the engineer who always comes to work late.

b. The manager scheduled a meeting with the engineer who I used to work with.

c. The manager scheduled a meeting with the engineer who always comes to work late.

On our judgment, neither (13a) nor (13b) strongly invites an inference about the reason for the meeting. On the other hand, $(13 \mathrm{c})$ does, evoking the idea that the reason the manager scheduled a meeting is because the engineer always comes to work late (e.g., the manager intends to discipline the engineer). Whereas the differences across examples (9-10) suggest that the relative clause is the trigger for the extrasemantic inferences when they obtain, (13a-c) show the inference cannot be tied to the occurrence of any one constituent. That is, (13a) lacks an inference even though it features the same relative clause as (13c), and (13b) lacks an inference even though it features the same subject noun phrase as (13c). Thus, it is only the co-occurrence of multiple constituents that gives rise to the eliciture. But if that is the case, then the only possible trigger for the inference would be machinery that notices the potential associations among the meanings of constituents and serves up the candidate strengthening — that is, the very machinery we have for establishing 
relevance itself. Hence, an appeal to the relevance norm puts the cart before the horse: the machinery for establishing relevance in such cases receives no external trigger; it is already running as part of the normal interpretative process.

In light of the drawbacks involving the Maxim of Relation, an alternative Gricean line of attack would be to indict either of the Manner or Quantity maxims as the trigger for the inferences. However, elicitures do not pattern with implicatures that arise from potential violations of these maxims either. Compare (14a-c).

a. The company fired the employee who came in late. $(=9)$

b. The company fired the employee who has red hair. $(=10)$

c. The company fired the employee who has red hair, a beard, and glasses.

As we have discussed, (14a) will generally be taken to convey the information that the employee's lateness was a cause of his firing, even though it is neither more prolix nor more informative (in any relevant sense) than alternatives containing competing referring expressions, such as (14b), that do not evoke the inference. Further, example (14c) is more prolix than (14a), yet does not yield the inference that the employee's red hair, beard, and glasses were causes of his firing. What the injunctions against prolixity and overinformativity $d o$ predict is that (14c) may well be odd in a situation in which there is only one employee with red hair and the interlocutors are aware of this - i.e., in a situation in which the less prolix/informative relative clause in (14b) would have sufficed. But as these examples show, this effect is orthogonal to the question of under what conditions a cause will be inferred from the relative clause. We therefore conclude that these inferences need not be triggered by violations of Gricean (or other) norms.

Another possible line of attack would be to characterize our cases as a variety of Bach's IMPLICITURE (or, for Relevance Theorists, part of the EXPLICATURE of an utterance). Examples (15-16) are of the sort commonly cited.

(15) Donald is too crazy. [to be a serious contender for President]

(16) I haven't had breakfast. [today]

For Bach, implicitures are enrichments that a hearer makes for one of two reasons. The first is "because the utterance is semantically underdeterminate and completion is required" (Bach 1994: 126) in order to assign a truth value. The enrichment in (15) arises for this reason, as the utterance cannot be evaluated without knowing with respect to what Donald is too crazy. The second reason is "because what is being communicated is an expanded version of the proposition expressed" (p. 126), a situation triggered by a hearer recognizing "that a speaker cannot be plausibly taken, and therefore does not intend to be taken, to mean what he is saying" (p. 136). The enrichment in (16) arises for this reason, as the speaker is unlikely to be claiming 
that she has never had breakfast, and hence the meaning is narrowed to apply to the current day. In a similar vein, Sperber \& Wilson (1986: 174) likewise hold that explicatures arise because the semantic representations fixed by utterances are insufficiently determinate, and hence must be inferentially enriched, "before they can be taken to represent anything of interest".

Elicitures fail to pattern with these cases in two respects. First, like implicatures, expansions in such examples are, as we just noted, the result of rescue strategies triggered by a species of interpretative failure. In contrast, elicitures do not appear to depend on any kind of incompleteness or infelicity, and are not triggered by a grammatical shortcoming, a norm violation, nor any question on the part of the hearer about the plausibility of the unenriched meaning of the utterance. Second, implicitures/explicatures are restricted to cases involving the developments to the logical form of an utterance. Elicitures, on the other hand, do not yield refinements to the logical form of the utterance in which the associated constituents occur. Instead, they give rise to additional propositions that sit alongside the meaning of the utterance: The company fired the employee who came in late and the lateness was the reason for the firing.

Hence, in opposition to these mechanisms that give rise to enrichment, we argue that elicitures arise not from failure-triggered rescue strategies, but instead from the more basic, associative mechanisms used to establish coherence between clauses as described in $\S 2-\S 3$.

\section{Presupposition and domain restriction}

Thus far we have argued that the enrichments associated with examples such as (9) are not the result of implicature or impliciture/explicature, but instead from the process we have dubbed eliciture. Crucial to eliciture is the idea that certain types of knowledge are presupposed by the speaker, and indeed the speaker intends that the hearer recognize this fact and use it to draw the inference in question.

We now return to examples (1-2), in which domain restriction is at play. It is well-known that context can restrict the domains of various sorts of natural language expressions, including quantifiers, the antecedents of conditionals, generics, and habituals. Witness the pedestrian case of entity level quantification in (17a):

a. Every student will get an A.

b. Every student [ in the contextually-salient class ] will get an A.

In a typical context, in uttering the phrase every student the speaker does not intend to make an assertion about every student in the world, but instead only to a more restricted set, e.g. those in a particular class as in (17b). 
Operators that quantify over situations, of course, are subject to domain restriction as well. That is, such operators rarely quantify over all times or events, but instead over more narrow domains that are restricted by properties of the utterance and the discourse context. Presupposition is one such property. For instance, as von Fintel (1994) discusses at length, adverbial quantifiers interact with the focus-presupposition partition, resulting in the accommodation of the presupposition component of the quantifier's scope into its domain restriction. So when a speaker utters (18):

\section{Snodgrass usually shows up to work $[\mathrm{LATE}]_{F}$.}

she does not mean that, considering all events that Snodgrass is engaged in, most are instances of him showing up to work late. Instead, she intends to convey that when Snodgrass shows up to work, he is usually late. This restriction is recoverable from the information structure associated with (18): the noun late receives narrow focus, leaving the presupposition as Snodgrass shows up to work $X$. This presupposition in turn provides the basis for the domain restriction, yielding the meaning by which in those situations in which Snodgrass is showing up to work (trivially, at some time), he is usually late.

The role of presupposition in the calculation of domain restriction does not stop there, however. In many cases, the events expressed by utterances presuppose that certain states of the world hold at the time the event occurs. Consider (19a-c), from Schubert \& Pelletier $(1987,1989)$.

(19) John usually beats Marvin at ping pong.

b. Cats always land on their feet.

c. Robin Hood never misses.

Again, in all of these cases the quantification is intended to apply not to all situations, but only to a more restricted set. For instance, (19a) does not mean that at any given time John is likely to be beating Marvin at ping pong, but instead only at those times at which they are playing ping pong. Sentence (19b) quantifies only over those situations in which a cat is falling to the ground, and likewise (19c) quantifies over those situations in which Robin Hood is shooting an arrow. The property common to all of these cases is that the type of event expressed in the predicate presupposes another type of event that ultimately restricts the domain of quantification: someone beating someone else at a game presupposes that the event participants are playing the game, landing presupposes an immediately prior state of falling, and missing a target presupposes that one has just shot at it.

Our point here is twofold. First, when faced with an operator that quantifies over situations, part of the hearer's job is to infer what situations are being quantified 
over. Second, presuppositions that the speaker makes as part of communicating her intended message can serve to constrain the set of situations being quantified over.

\section{Analysis}

The tools are now in place to explain the interpretations of our core cases. In the examples just surveyed, presuppositions that project from the scope of a quantifier serve to constrain the set of situations being quantified over. The scenario for examples like (1) is different in at least two respects: the presupposition responsible for the interpretive effect is triggered by material that lies in the restrictor of the quantifier rather than its scope, and the presupposed information comes in the form of a defeasible causal law. This notwithstanding, we see the underlying interpretive processes as following a line similar to the more familiar examples. Specifically, upon a speaker's uttering a quantified sentence with an intended eliciture that relies on a causal presupposition, the hearer infers that the domain of quantification is restricted to those accessible situations in which the body of the presupposed rule holds.

Consider a context with a speaker who utters sentence (1), repeated below as (20), and the representation for it shown in (21):

(20) Every time the company fires an employee who comes in late, a union complaint is lodged.

$$
\begin{aligned}
& \forall s_{\mathrm{C}}\left[\forall x, e_{1}, e_{2} \leq_{p} s\right. \\
& \quad\left[\text { employee }(x) \& \text { come_in_late }\left(e_{1}\right)(x) \& \text { fire }\left(e_{2}\right)(\text { employer }(x))(x)\right. \\
& \left.\quad \Rightarrow \exists e_{3} \leq_{p} s\left[\text { file_complaint_against }\left(e_{3}\right)(\text { union }(x))(\text { employer }(x))\right]\right]
\end{aligned}
$$

The subscript $\mathrm{C}$ on the term $s_{\mathrm{C}}$ signifies that the set of situations being quantified over may be restricted by the operative context. And indeed, part of the hearer's interpretive task is to identify any such restrictions. At the same time, our hearer reasons, in light of the speaker's choice of referring expression, that she intends to convey a causal eliciture, one that presupposes that axiom (4), repeated as (22), is in the common ground.

$$
\begin{aligned}
& \lambda s . \forall s^{\prime}\left[\operatorname{Acc}_{\mathrm{C}}(s)\left(s^{\prime}\right) \&\right. \\
& \exists x, e_{1}, e_{2} \leq_{p} s^{\prime} \\
& \quad \text { employee }(x) \text { \& come_in_late }\left(e_{1}\right)(x) \& \\
& \quad \text { iire }\left(e_{2}\right)(\text { employer }(x))(x) \& t_{e_{1}}<t_{e_{2}} \\
& \left.\left.\quad \Rightarrow \operatorname{cause}\left(e_{1}\right)\left(e_{2}\right) \leq_{p} s^{\prime}\right]\right]
\end{aligned}
$$

But as we have previously discussed, the conditional captured by this axiom applies only to those accessible situations that meet certain background assumptions, i.e. those 'best' situations as served up by an epistemic modal base and stereotypical 
ordering source. As such, it follows from the recognition of the speaker's intention to communicate an eliciture that relies on (22) that she also intends to restrict the domain of quantification to those situations in which the conditional holds. Without accommodating the requisite domain restriction there can be no eliciture, for the enrichment would not hold in all the situations being quantified over.

The key point is that the inference process is essentially the same as with simpler cases that do not involve quantification as in (9), except instead of identifying what kind of situation is being described during utterance interpretation, the hearer is identifying what kinds of situations are being quantified over. This is how an enrichment that has the status of a defeasible, pragmatic inference in a case like (9) takes on truth-conditional import when it serves to restrict the domain over which a quantifier applies, just like other, more familiar sorts of pragmatically-determined domain restriction.

In this section we have focused on the quantified case in (1). However, the interpretation of the antecedent of the conditional in (2) would follow an analogous process. Specifically, on a restrictor analysis of conditionals, the set of situations over which the if-clause restricts interpretation will be narrowed to those in which a causal relationship holds in the same way as we saw for quantified sentences, in light of the recognition by the hearer that the speaker intends the eliciture to be drawn, given the causal axiom in (22).

\section{Reanalysis of pragmatic intrusion}

In the previous section, a puzzling case of pragmatic intrusion into truth conditions was resolved via an interaction among pragmatic presupposition, the processes that underlie the establishment of coherence in discourse, and the identification of domain restriction for operators in context. Key to our argument is that the enrichment is not an implicature, nor any other type of post-semantic expansion.

Since at least Cohen (1971), the apparent possible truth of examples like (23) - which, given the standard boolean semantics for conjunction, should express a contradiction - has been regarded as problematic for theories (e.g., Grice's) that treat pragmatic enrichment as operating exclusively on the outputs of semantic interpretation:

(23) If an employee chastises management and gets fired, then union leaders will file a free-speech grievance, but if an employee gets fired and chastises management, they won't.

Because Levinson (2000) treats the enrichments in the antecedents of each conditional as implicatures (specifically, Manner-/I-implicatures), he is forced to conclude 
that, contrary to the standard Gricean paradigm, implicatures can intrude upon truth-conditional semantic content.

Our analysis of (2), however, suggests that this concession may be premature. As we have argued, the enrichments at play in both intraclausal cases like (2) and interclausal cases like (23) are presupposition-based, coherence-driven inferences, and not implicatures. Whereas the antecedents of the two conditionals in (23) may be truth-conditionally equivalent, the causal presuppositions that they rely on, and hence their domain restrictions, are not: the first presupposes that chastising management can cause one to get fired, whereas the second presupposes that getting fired can cause one to chastise management.

Let us refer to the chastising as $e_{1}$ and the firing as $e_{2}$. The first antecedent, represented in (24), presupposes that chastising management can cause one to get fired as captured by (25), resulting in a set of accessible situations in which $\operatorname{cause}\left(e_{1}\right)\left(e_{2}\right)$ is true.

$$
\begin{aligned}
& \forall s_{\mathrm{C}}\left[\forall x, e_{1}, e_{2} \leq_{p} s\right. \\
& \quad\left[\text { employee }(x) \text { \& chastise }\left(e_{1}\right)(x)(\text { employer }(x)) \&\right. \\
& \quad \text { fire }\left(e_{2}\right)(\text { employer }(x))(x) \\
& \left.\Rightarrow \exists e_{3} \leq_{p} s\left[\text { file_complaint }\left(e_{3}\right)(\text { union }(x))(\text { employer }(x))\right]\right] \\
& \begin{array}{r}
\lambda s . \forall s^{\prime}\left[\text { Acc }_{\mathrm{C}}(s)\left(s^{\prime}\right) \&\right. \\
\forall x, e_{1}, e_{2} \leq_{p} s^{\prime}\left[\text { employee }(x) \& \text { chastise }\left(e_{1}\right)(x)(\text { employer }(x)) \&\right. \\
\text { fire }\left(e_{2}\right)(\text { employer }(x))(x) \& t_{e_{1}}<t_{e_{2}} \\
\left.\left.\Rightarrow \text { cause }\left(e_{1}\right)\left(e_{2}\right) \leq_{p} s^{\prime}\right]\right]
\end{array}
\end{aligned}
$$

The second antecedent, represented in (26), presupposes that getting fired can cause one to chastise management as captured by (27), resulting in a set of accessible situations in which cause $\left(e_{2}\right)\left(e_{1}\right)$ is true.

$$
\begin{aligned}
& \forall s_{\mathrm{C}}\left[\forall x, e_{1}, e_{2} \leq_{p} s\right. \\
& \text { [employee }(x) \& \text { chastise }\left(e_{1}\right)(x)(\text { employer }(x)) \& \\
& \text { fire }\left(e_{2}\right)(\text { employer }(x))(x) \\
& \left.\Rightarrow \neg \exists e_{3} \leq{ }_{p} s\left[\text { file_complaint }\left(e_{3}\right)(\text { union }(x))(\text { employer }(x))\right]\right] \\
& \lambda s . \forall s^{\prime}\left[A c c_{\mathrm{C}}(s)\left(s^{\prime}\right) \&\right. \\
& \forall x, e_{1}, e_{2} \leq_{p} s^{\prime}\left[\text { employee }(x) \& \text { chastise }\left(e_{1}\right)(x)(\text { employer }(x)) \&\right. \\
& \text { fire }\left(e_{2}\right)(\text { employer }(x))(x) \& t_{e_{1}}>t_{e_{2}} \\
& \left.\left.\Rightarrow \operatorname{cause}\left(e_{2}\right)\left(e_{1}\right) \leq_{p} s^{\prime}\right]\right]
\end{aligned}
$$

Thus, whereas (24) and (26) would appear to be contradictory (they differ only in the polarity of the consequent), they are in fact not, since they are evaluated with respect to different domains of quantification. It is therefore expected on our view 
that conjunct ordering would have truth-conditional import in conditionals, without having to concede that purportedly post-semantic enrichments intrude upon semantic content. ${ }^{4}$

\section{Conclusion}

Examples like (1-2) presented a puzzle: why would a pragmatic enrichment, one with the apparent hallmarks of a post-semantic inference and without any linguistic or other type of mandate, have truth-conditional import? We have argued that such examples receive a natural explanation by way of a novel interaction of otherwise familiar pragmatic processes: pragmatic presupposition, coherence establishment, and the computation of domain restriction for operators that quantify over situations. The proper analysis of such cases requires recognizing that coherence-driven inferences are not species of implicature, impliciture, or other forms of pragmatic enrichment

4 One might ask how the correct temporal orderings come to be established for each of the antecedents in (23). (Thanks to Ivano Caponigro for bringing this issue to our attention.) As we mentioned in footnote 1 , in cases in which an ordering is required by a presupposed causal law but is not specified linguistically by the utterance, the analysis necessitates that the ordering be accommodated by the hearer. However, there are two orderings that could be accommodated for (23) that would avoid a contradiction: the intended one whereby forward movement of time is inferred between the conjuncts in each antecedent, and a second in which the backward movement of time is inferred in each case, i.e., whereby the clauses are understood as describing an effect followed by a cause. On this construal, axioms (25) and (27) would be presupposed by the second and first conditional antecedents respectively, rather than the other way around. As the latter possibility yields a consistent reading, what rules it out?

On an analysis like ours in which orderings between events described with simple tenses are constrained by the establishment of coherence relations (Lascarides \& Asher 1993; Kehler 2002), the second reading is eliminated by the fact that the conjunction and is inconsistent with relations that require the events to occur in reverse order, particularly Explanation, the relation that the axioms would support on the second reading. That is, whereas example (i) has an Explanation construal whereby the embezzling preceded (and indeed, caused) the firing, this reading is eliminated in a variant in which the clauses are conjoined with and as in (ii).

(i) Snodgrass was fired. He embezzled money.

(ii) Snodgrass was fired and he embezzled money.

Hence, the antecedents of the conditionals in (23) cannot receive the second logically consistent reading, leaving the intended meaning as the sole remaining one.

Note that the pervasiveness of examples like (i) in discourse is problematic for other possible explanations of the effect, for instance treating the simple past tense as anaphoric (in which case, under suitable assumptions, the temporal order would be linguistically expressed and indeed encoded in the logical form), or following Levinson by treating the effect as an implicature based on a principle deriving from Grice's Maxim of Manner, specifically the injunction to "be orderly". Both approaches should apply equally to conjoined-clause and separate-clause discourses like (i)-(ii), leaving the existence of a reading of (i) in which the events move backward in time a mystery. 
upon which the field has focused. The analysis extends directly to cases like (23), which have been used to argue for the intrusion of implicature into truth-conditional meaning.

In this paper we have focused on causal elicitures that result from associations between the meaning of a verb (e.g., fire) and that of a relative clause (e.g., who came in late). The analysis, of course, is intended to extend more broadly to other cases in which elicitures arise. Consider the situation in which an eliciture results from the combination of a particular choice of a nominal and a predicate, as in (28).

(28) Every time a factory worker gets injured by a machine, the union performs an investigation.

(29) Every time a factory worker falls seriously ill, the union helps them resolve any problems with the insurance company.

It seems reasonable to think that, even in light of what (28) says, the union might not investigate accidents that occur at a worker's home (e.g., when building a hobby project in a home shop). That is to say, the example invites the eliciture that the worker has to be working at the factory at the time of the accident. An analogous eliciture seems much less inevitable in (29), however, whereby the situations being quantified over may well include ones in which the worker falls ill at places other than work. (See Cohen \& Kehler (2016) for further discussion of such cases.) Notably, the elicitures in such cases are not causal, but are instead based on a type of spatio-temporal contiguity-based coherence. The formal characterization of the knowledge being presupposed and its use in inferring domain restriction in such examples is a topic for future work.

\section{Acknowledgments}

Thanks to Ivano Caponigro, participants of the SemanticsBabble reading group at UC San Diego, attendees of SALT (especially Hans Kamp, Lauri Karttunen, and Stanley Peters), and an audience at Boğaziçi University for helpful comments and discussion.

\section{References}

Asher, Nicholas \& Alex Lascarides. 2003. Logics of Conversation. Cambridge: Cambridge University Press.

Bach, Kent. 1994. Conversational impliciture. Mind and Language 9(2). 124-162. Chierchia, Gennaro \& Sally McConnell-Ginet. 2000. Meaning and Grammar: An Introduction to Semantics. MIT Press.

Cohen, Jonathan \& Andrew Kehler. 2016. Conversational eliciture. Under review. 
Cohen, L. Jonathan. 1971. Some remarks on Grice's views about the logical particles of natural language. In Yehoshua Bar-Hillel (ed.), Pragmatics of Natural Languages, 50-68. Dordrecht: Reidel.

von Fintel, Kai. 1994. Restrictions on quantifier domains: University of Massachusetts Amherst PhD dissertation.

von Fintel, Kai. 2004. Would you believe it? The King of France is back! (Presuppositions and truth-value intuitions). In Marga Reimer \& Anne Bezuidenhout (eds.), Descriptions and Beyond, 269-296. Oxford University Press.

Grice, H. P. 1975. Logic and conversation. In Peter Cole \& Jerry Morgan (eds.), Speech Acts, 41-58. New York: Academic Press.

Hobbs, Jerry R. 1990. Literature and Cognition. Stanford, CA: CSLI Lecture Notes 21.

Kehler, Andrew. 2002. Coherence, Reference, and the Theory of Grammar. CSLI Publications.

Kratzer, Angelika. 1981. The notional category of modality. In Hans Jürgen Eikmeyer \& Hannes Riesser (eds.), Words, Worlds, and Contexts, 38-74. Berlin, New York: Walter de Gruyter.

Lascarides, Alex \& Nicholas Asher. 1993. Temporal interpretation, discourse relations, and common sense entailment. Linguistics and Philosophy 16(5). 437-493.

Levinson, Stephen C. 2000. Presumptive Meanings. Cambridge, MA: MIT Press.

Portner, Paul. 2009. Modality. Oxford: Oxford University Press.

Potts, Christopher. 2015. Presupposition and implicature. In Shalom Lappin \& Chris Fox (eds.), The Handbook of Contemporary Semantic Theory, 168-202. Wiley-Blackwell 2nd edn. doi:10.1002/9781118882139.ch6.

Schubert, Lenhart K. \& Francis Jeffry Pelletier. 1987. Problems in the representation of the logical form of generics, plurals, and mass nouns. In Ernest Lepore (ed.), New Directions in Semantics, Academic Press.

Schubert, Lenhart K. \& Francis Jeffry Pelletier. 1989. Generically speaking, or, using discourse representation theory to interpret generics. In Gennaro Chierchia, Barbara H. Partee \& Raymond Turner (eds.), Properties, Types and Meaning. Volume II: Semantics Issues, 193-268. Dordrecht: Kluwer.

Shanon, Benny. 1976. On the two kinds of presupposition in natural language. Foundations of Language 14(2). 247-249.

Sperber, Dan \& Deirdre Wilson. 1986. Relevance: Communication and Cognition. Cambridge, MA: Harvard University Press.

Stalnaker, Robert. 1974. Pragmatic presuppositions. In Milton K. Munitz \& Peter Unger (eds.), Semantics and Philosophy, 197-214. New York University Press.

Stalnaker, Robert. 1979. Assertion. In Peter Cole (ed.), Syntax and Semantics 9: Pragmatics, 315-332. New York: Academic Press. 
Eliciture and domain restriction

Stalnaker, Robert. 1998. On the representation of context. Journal of Logic, Language, and Information 7. 3-19.

Toosarvandani, Maziar. 2014. Contrast and the structure of discourse. Semantics and Pragmatics 7(4). 1-57.

Andrew Kehler

Department of Linguistics

University of California, San Diego

9500 Gilman Drive

La Jolla, CA 92093-0108

akehler@ucsd.edu
Jonathan Cohen

Department of Philosophy

University of California, San Diego 9500 Gilman Drive

La Jolla, CA 92093-0119

joncohen@aardvark.ucsd.edu 